\title{
Accidental finding of a toothpick in the porta hepatis during laparoscopic cholecystectomy: a case report
}

\author{
Waleed Al-Khyatt ${ }^{*}$, Farhan Rashid and Syed Y Iftikhar
}

\begin{abstract}
Introduction: Unintentional ingestion of a toothpick is not an uncommon event. Often the ingested toothpicks spontaneously pass through the gut without sequelae. However, serious complications can happen when these sharp objects migrate through the gastrointestinal wall.

Case presentation: In the current report, we describe the case of a 37-year-old Caucasian woman with an incidental finding of a toothpick in the porta hepatis during laparoscopic cholecystectomy for symptomatic gall stones.

Conclusion: Toothpick ingestion is not an uncommon event and can predispose patients to serious complications. In this particular case, the toothpick was only discovered at the time of unrelated surgery. Therefore, it was important during surgery to exclude any related or missed injury to the adjacent structures by this sharp object.
\end{abstract}

\section{Introduction}

Unintentional ingestion of a toothpick is not an uncommon event. Often the ingested toothpicks spontaneously pass through the gut without sequelae [1]. However, serious complications can happen when these sharp objects migrate through the gastrointestinal wall [2]. Patients with ingested toothpicks in the gastrointestinal tract typically have no recollection of the event. Symptoms related to toothpick ingestion are often variable and non-specific $[3,4]$. In the current report, we describe the case of a 37-year-old Caucasian woman with an incidental finding of a toothpick in the porta hepatis during laparoscopic cholecystectomy for symptomatic gall stones.

\section{Case presentation}

A 37-year-old Caucasian woman presented to our facility with recurrent attacks of upper abdominal pain over a six-month period. Otherwise, she was fit and well with no significant medical history. The results of general and abdominal examinations were normal. Results from

\footnotetext{
* Correspondence: waleed.al-khyatt@nottingham.ac.uk Division of Upper Gl Surgery, School of Graduate Entry Medicine and Health, University of Nottingham, Royal Derby Hospital, Uttoxeter Road, Derby, DE22 3DT, UK
}

her initial blood tests showed deranged liver function of the obstructive type. An abdominal ultrasound scan revealed a thickened gall bladder wall containing multiple gall stones. A magnetic resonance cholangiopancreatography (MRCP) study showed multiple gall stones; however, there was no choledocholithiasis. Our patient underwent elective laparoscopic cholecystectomy and on-table cholangiogram (OTC) for symptomatic gall stones. The procedure was performed with a standard Veress needle using the pneumoperitoneum technique, with four ports for maintenance of intraperitoneal pressure at $12 \mathrm{mmHg}$ and a pneumoperitoneum time of 55 minutes. During surgery, a foreign body was found wrapped in the omentum and stuck to the liver at the base of the falciform ligament near the porta hepatis (Figure 1). With laparoscopic dissection, this object was removed and revealed to be a foreign body (a toothpick; Figure 2). The duodenum, stomach and hepatic flexure were assessed thoroughly; no evidence of perforation or injury was identified. The laparoscopic cholecystectomy and OTC were performed as planned. Our patient made an uneventful post-operative recovery. During her follow up visit, our patient was informed of this unusual finding. She was able to recall the event of probable accidental ingestion of a toothpick seven years previously. 


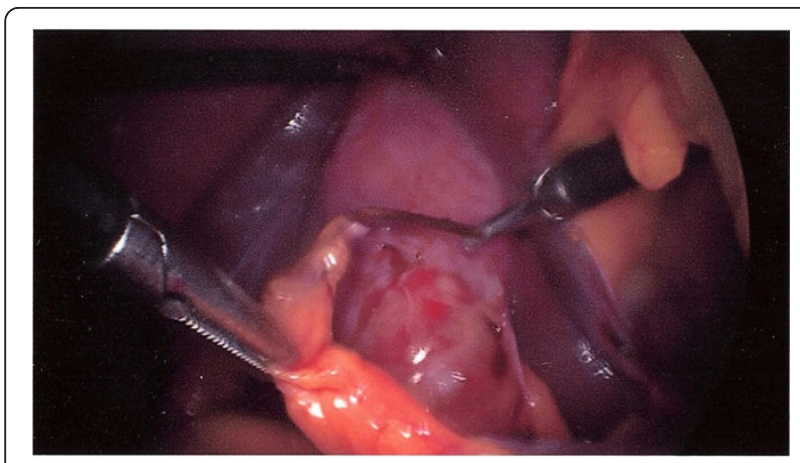

Figure 1 Toothpick accidentally found in porta hepatis during laparoscopic cholecystectomy.

However, she could not remember any significant related illness subsequently.

\section{Discussion}

Foreign body ingestion is a common event which may happen accidentally or intentionally [1]. Many such ingested foreign bodies pass through the gastrointestinal tract uneventfully [5]. However, in the case of sharp objects such as toothpicks, serious complications can be unavoidable. Ingested toothpicks tend to stick in places where there is natural narrowing, sharp angulations, or congenital gastrointestinal malformation [6]. Li et al. in his systemic review of 57 cases found that the duodenum and sigmoid colon are the commonest sites for perforation. Patients diagnosed with perforation of the gastrointestinal tract due to toothpick ingestion are usually men $(88 \%)$ who present with abdominal pain $(70 \%)$ or gastrointestinal bleeding (7\%). Only $12 \%$ of patients had any recollection of swallowing a toothpick. In patients who remembered the event, the onset of symptoms ranged from less than a day to 15 years. The duration of symptoms before diagnosis ranged from one day to nine months [2]. Toothpick ingestion may cause severe, sometimes fatal, internal injuries due to gastrointestinal

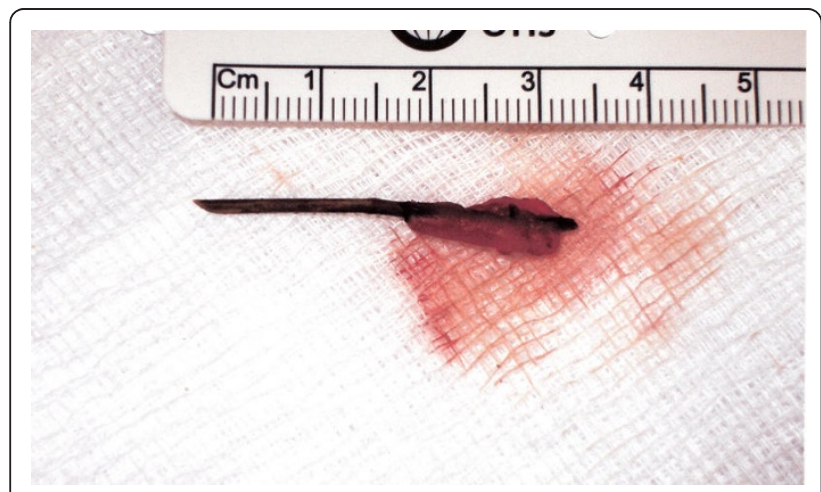

Figure 2 The toothpick after laparoscopic extraction. perforation and migration to adjacent structures $[2,4,7]$. Diagnosis of toothpick injury can be quite difficult as patients frequently have vague symptoms with no specific physical findings $[2,3,6]$. Imaging studies are often of limited value as wooden toothpicks are radiolucent in plain films. However, ultrasonography and computed tomography (CT) have been recommended as useful tools for the detection of these foreign bodies, which are often hyperechoic on ultrasonography and of high density on CT $[8,9]$. Most of the time, the final diagnosis can be achieved through endoscopy, laparoscopy, or laparotomy $[4,10]$. However, many patients are completely asymptomatic, and objects such as toothpicks may only be uncovered accidentally during other surgical procedures [11].

What is particular about this case is that the foreign body was only discovered at the time of surgery. Interestingly, after surgery, our patient was able to recall the event of toothpick ingestion; however, she did not recall any significant symptoms around the time of the event. A retrospective review of her pre-operative abdominal ultrasonography and MRCP images did not reveal any missed evidence of this foreign body. This could be explained by the fact that there was no inflammatory reaction surrounding the toothpick, which would have raised suspicion of this finding. Very slow migration of the toothpick may probably explain the absence of symptoms in this case [11]. A high index of suspicion of foreign body ingestion should be considered during the assessment of upper abdominal pain of recent onset [2,6,12]. In addition, it is important to exclude any related or missed injury to the adjacent structures when these sharp objects are encountered accidentally during surgery.

\section{Conclusion}

Toothpick ingestion is not an uncommon event and could predispose a patient to serious complications. A high index of suspicion of foreign body ingestion should be considered during the assessment of upper abdominal pain of recent onset. In this particular case, the toothpick was only discovered at the time of surgery; Therefore, it was important during surgery to exclude any related or missed injury to the adjacent structures by this sharp object.

\section{Consent}

Written informed consent was obtained from the patient for publication of this case report and any accompanying images. A copy of the written consent is available for review by the Editor-in-Chief of this journal.

Authors' contributions

WA, FR an SYI were major contributors to writing the manuscript. SYI performed the procedure. All authors read and approved the final manuscript. 


\section{Competing interests}

The authors declare that they have no competing interests.

Received: 9 March 2011 Accepted: 30 August 2011

Published: 30 August 2011

\section{References}

1. Rashid F, Davies L, Iftikhar SY: Magnetised intragastric foreign body collection and autism: an advice for carers and literature review. Autism 2010, 14:139-145.

2. Li SF, Ender K: Toothpick injury mimicking renal colic: case report and systematic review. J Emerg Med 2002, 23:35-38.

3. Zezos P, Oikonomou A, Souftas V, Gkotsis D, Pitiakoudis M, Kouklakis G: Endoscopic removal of a toothpick perforating the sigmoid colon and causing chronic abdominal pain: a case report. Cases J 2009, 2:8469.

4. Tonkic A, Kulic D, Peric M, Tonkic M, Bogdanovic Z: Bacteremia caused by a swallowed toothpick impacted in the gastric mucosa. Case Rep Gastroenterol 2011, 5:227-231.

5. Goh BK, Chow PK, Quah HM, Ong HS, Eu KW, Ooi LL, Wong WK: Perforation of the gastrointestinal tract secondary to ingestion of foreign bodies. World J Surg 2006, 30:372-377.

6. Nigri GR, Di Giulio E, Di Nardo R, Pezzoli F, D'Angelo F, Aurello P, Ravaioli M, Ramacciato G: Duodenal perforation and right hydronephrosis due to toothpick ingestion. J Emerg Med 2008, 34:55-57.

7. Matsubara M, Hirasaki S, Suzuki S: Gastric penetration by an ingested toothpick successfully managed with computed tomography and endoscopy. Intern Med 2007, 46:971-974.

8. Liu HJ, Liang CH, Huang B, Xie SF, Wang GY: Migration of a swallowed toothpick into the liver: the value of multiplanar CT. Br J Radiol 2009, 82: e79-e81.

9. Chiang TH, Liu KL, Lee YC, Chiu HM, Lin JT, Wang HP: Sonographic diagnosis of a toothpick traversing the duodenum and penetrating into the liver. J Clin Ultrasound 2006, 34:237-240.

10. Rioux M, Langis P: Sonographic detection of clinically unsuspected swallowed toothpicks and their gastrointestinal complications. J Clin Ultrasound 1994, 22:483-490.

11. Porcu A, Dessanti A, Feo CF, Dettori G: Asymptomatic gastric perforation by a toothpick. A case report. Dig Surg 1999, 16:437-438.

12. Saccà N, Rodino' S, D'Amico T, Fragomeni A, Sebkova L, Giglio A: An unintentional ingestion of a toothpick: a case report. Dig Liver Dis 2005, 37:983-984.

doi:10.1186/1752-1947-5-421

Cite this article as: Al-Khyatt et al: Accidental finding of a toothpick in the porta hepatis during laparoscopic cholecystectomy: a case report. Journal of Medical Case Reports 2011 5:421.

\section{Submit your next manuscript to BioMed Central and take full advantage of:}

- Convenient online submission

- Thorough peer review

- No space constraints or color figure charges

- Immediate publication on acceptance

- Inclusion in PubMed, CAS, Scopus and Google Scholar

- Research which is freely available for redistribution

Submit your manuscript at www.biomedcentral.com/submit
Biomed Central 